\title{
Hunian Vertikal dengan Konsep Waterfront Architecture
}

\author{
Isnaeni Nur Chasanah dan Dewi Septanti \\ Departemen Arsitektur, Fakultas Arsitektur, Desain dan Perencanaan, Institut Teknologi Sepuluh Nopember (ITS) \\ e-mail: dewi_s@arch.its.ac.id
}

\begin{abstract}
Abstrak-Bidang ekonomi menjadi salah satu faktor adanya urbanisasi. Akibatnya kaum urban harus menetap di sekitar tempat mereka bekerja dan membuat daerah perkotaan menjadi kawasan padat. Tingginya permintaan lahan untuk permukiman tidak diimbangi dengan ketersediaan lahan sehingga masyarakat mencari alternatif lahan kosong untuk tinggal misalnya bantaran rel, bantaran sungai, dan pinggiran kota. Bantaran sungai yang merupakan lahan ilegal menjadi salah satu berkembangnya kawasan kumuh karena dijadikan halaman belakang dari suatu kawasan. Hal ini seperti Sungai Kalimas yang dahulu kala menjadi pusat peradaban namun berangsur mengalami kemunduran dan penurunan citra kualitas sungai. Permasalahan diatas membutuhkan respon yaitu sebuah hunian vertikal di tepi sungai untuk menyiasati sempitnya lahan yang memiliki fasilitas untuk mengembangkan keterampilan penghuninya. Menggunakan pendekatan arsitektur perilaku, gagasan ini berusaha memindahkan masyarakat dari hunian horizontal menjadi hunian vertikal. Sebagai bangunan yang berada di tepi Sungai Kalimas, konsep waterfront architecture digunakan agar dapat selaras dengan lingkungan dan menjadikan sungai sebagai muka depan suatu kawasan. Perwujudan muka depan dari kawasan ini dengan adanya water-enjoyable-space yaitu zona transisi yang menjadikan tepian sungai menjadi ruang bersama dengan harapan menjadi muka depan bagi kawasan tersebut.
\end{abstract}

Kata Kunci-Arsitektur Perilaku, Hunian Vertikal, Waterfront Architecture.

\section{PENDAHULUAN}

$\mathrm{K}^{\circ}$ OTA adalah tempat bermukimnya warga kota, tempat bekerja, tempat kegiatan dalam bidang ekonomi, pemerintah, dan lain-lain [1]. Perkembangan daerah perkotaan melalui sektor industri dan perdagangan serta keinginan untuk memperoleh penghasilan merupakan faktor penyebab terjadinya urbanisasi [2]. Kaum urban berbondong-bondong mencari pekerjaan di kota dan mulai bermukim di kawasan perkotaan. Pekerjaan menuntut mereka menetap di sekitar tempat mereka bekerja, akibatnya daerah perkotaan menjadi kawasan padat.

Tingginya permintaan lahan untuk permukiman tidak diimbangi dengan ketersediaan lahan sehingga harga lahan di kota semakin mahal [3]. Masyarakat akhirnya mencari alternatif lain untuk memenuhi kebutuhan akan tempat tinggal dengan mencari lahan kosong di sekitar tempat bekerja. Hal ini mengakibatkan ruang-ruang kosong tak berpenghuni dijadikan lahan terbangun untuk bermukim. Misalnya berdirinya permukiman di bantaran rel, bantaran sungai, pinggiran kota, ruang hijau dan lain sebagainya. Bantaran sungai menjadi salah satu alternatif yang banyak dipilih untuk bermukim.

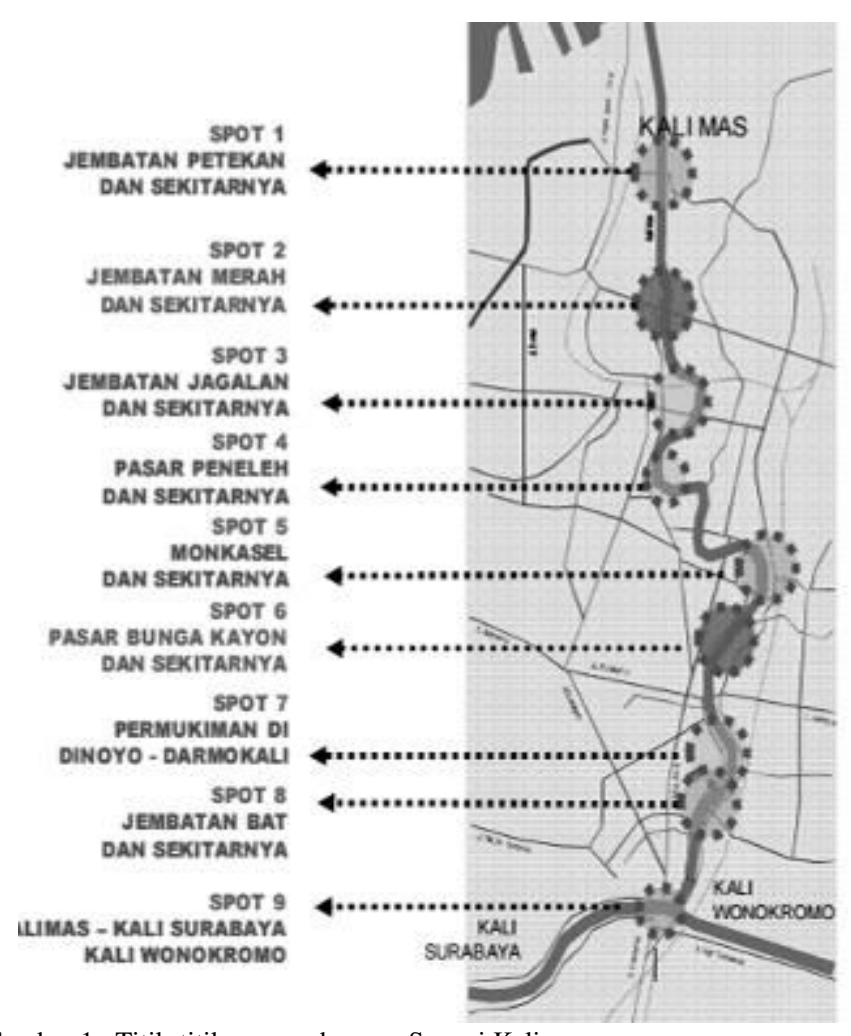

Gambar 1. Titik-titik pengembangan Sungai Kalimas.

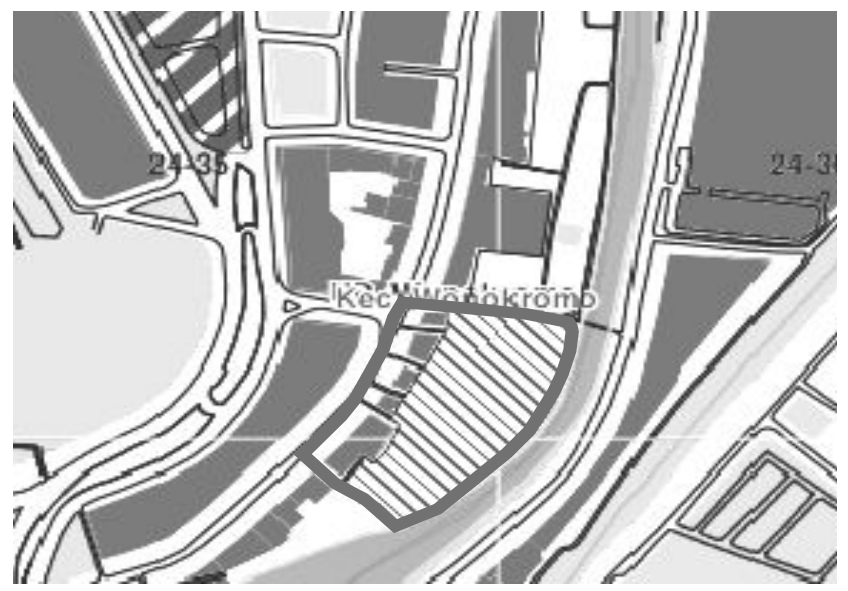

Gambar 2. Peruntukan lahan.

Sumber : http://petaperuntukan.surabaya.go.id/cktr-map/

Awalnya permukiman tumbuh di daerah tepi sungai karena para pemukim mendekati sumber air bagi kegiatan mereka sehari-hari [4]. Fenomena baru muncul ketika moda transportasi darat berkembang lebih dari transportasi sungai. Sungai sebagai muka depan beralih menjadi bagian belakang 


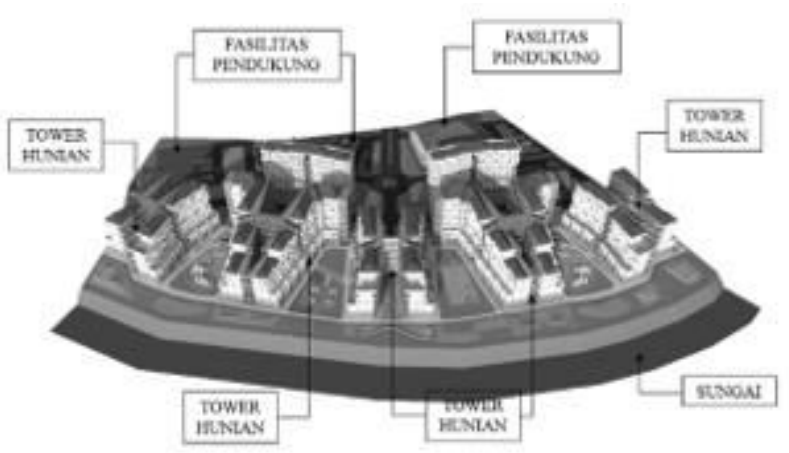

Gambar 3. Zonasi tapak berdasarkan peruntukan lahan dengan konsep residential waterfront.

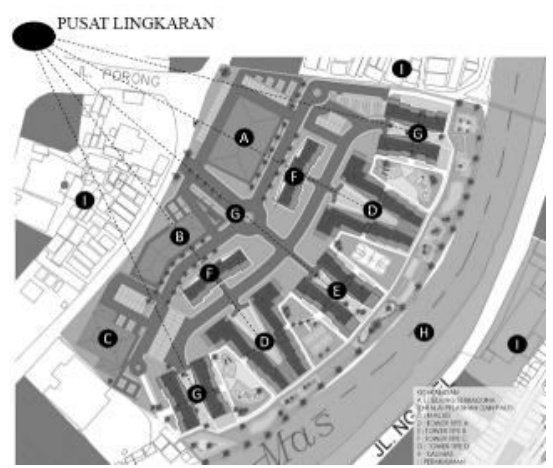

Gambar 4. Titik lingkaran yang terbentuk sebagai pusat dalam mengolah tatanan massa.

dari sebuah kawasan dan mulai ditinggalkan. Salah satu Sungai yang mengalami kemunduran nilai citra kualitas adalah Sungai Kalimas, Surabaya.

Cikal bakal kota Surabaya adalah sebuah perkampungan di atas air di muara Kalimas [5]. Kalimas berfungsi sebagai sarana transportasi utama masyarakat Surabaya yang menghubungkan pusat-pusat perdagangan penghasil rempahrempah dengan Pelabuhan Tanjung Perak [4]. Seiring perkembangan zaman, Kalimas seolah ditinggalkan. Kawasan di sekitar mulai turun nilainya, fasilitas serta infrastrukturnya tertinggal, serta kondisi sosial ekonominya tidak terintegrasi dengan wilayah lain lagi. Jika dilihat merupakan fenomena yang berangkat dari aspek ekonomi. Permasalahan utama dalam penghunian kawasan bantaran sungai adalah ketidakberdayaan sumber daya ekonomi, yang berdampak pada keterbatasan pendidikan dan ketrampilan yang dimiliki oleh penghuni [6].

Berbagai usaha dilakukan oleh Pemerintah Surabaya dengan melakukan pembangunan, revitalisasi, dan berbagai upaya lainnya untuk mempercantik Kalimas. Terdapat titik-titik pada Sungai Kalimas yang memiliki potensi untuk dikembangkan seperti gambar 1. Salah satu yang belum tersentuh adalah Spot 9 yang memiliki peruntukan sebagai permukiman di sekitarnya seperti pada gambar 2. Lahan ini berada di Jalan Darmokali dan memiliki luas $29.525 \mathrm{~m}^{2}$.

\section{METODA PERANCANGAN}

Pendekatan yang digunakan untuk memindahkan penghuni

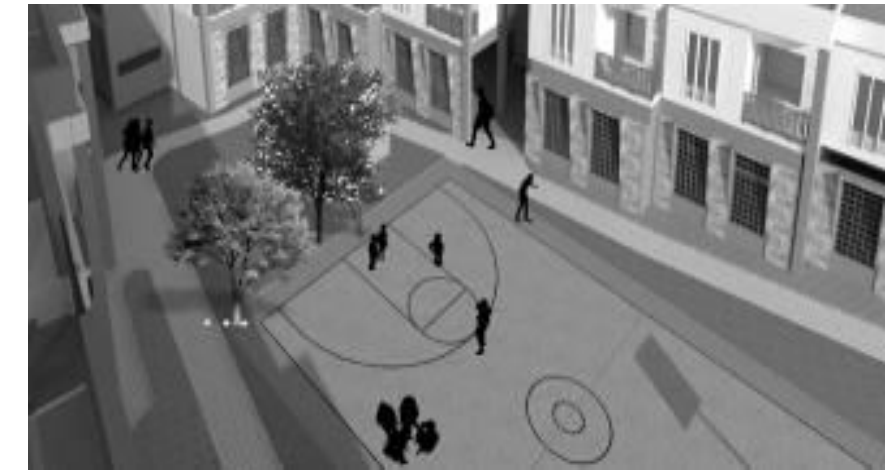

Gambar 5. Ilustrasi salah satu plaza diantara 2 tower yang berhadapan.

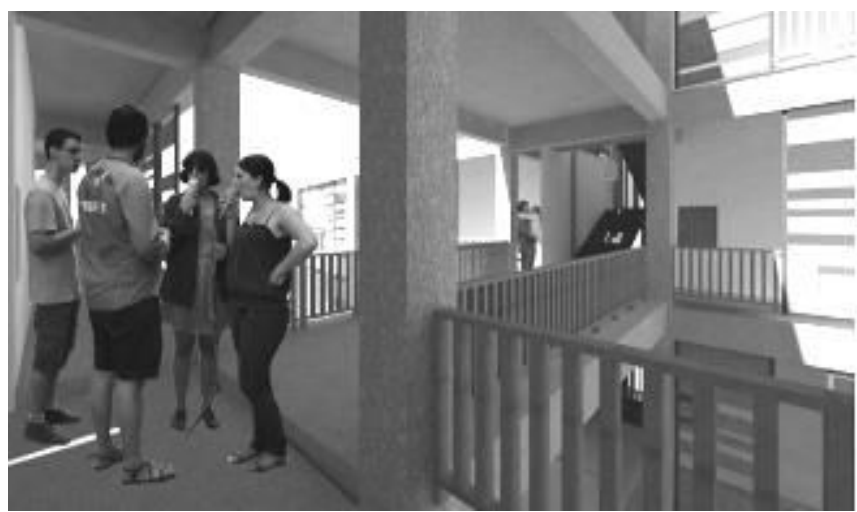

Gambar 6. Ilustrasi suasana jembatan penghubung dalam 1 tower.

dari horizontal ke vertikal adalah dengan menggunakan pendekatan arsitektur perilaku. Behavior mapping digambarkan dalam bentuk sketsa atau diagram mengenai suatu area dimana manusia melakukan berbagai kegiatannya Tujuannya adalah untuk menggambarkan perilaku dalam peta, mengidentifikasikan jenis dan frekuensi perilaku, serta menunjukkan kaitan antara perilaku tersebut dengan wujud perancangan yang spesifik [7]. Terdapat dua cara melakukan pemetaan yaitu:

\section{A. Place-centered mapping}

Teknik ini digunakan untuk mengetahui bagaimana manusia atau sekelompok manusia memanfaatkan, menggunakan dan mengakomodasikan perilakunya dalam suatu waktu pada tempat tertentu. Metode ini lebih menekankan perilaku secara umum seperti kebiasaan mereka yang memiliki kecenderungan untuk menggunakan sempadan sungai menjadi ruang bersama, baik untuk berkumpul, bercengkerama, mengobrol dengan tetangga, sampai memanfaatkan untuk kegiatan ekonomi seperti menjual makanan dan membuka warung kecil. Selain sempadan sungai, masyarakat juga menggunakan pertemuan jalan untuk berkumpul dan mengadakan acara. Perilaku tersebut yang akan diwujudkan di luar unit hunian dan kebanyakan berupa ruang-ruang bersama.

\section{B. Person-centered mapping}

Teknik ini menekankan pada pergerakan manusia pada periode waktu tertentu, dimana teknik ini berkaitan dengan tidak hanya satu tempat atau lokasi akan tetapi beberapa 


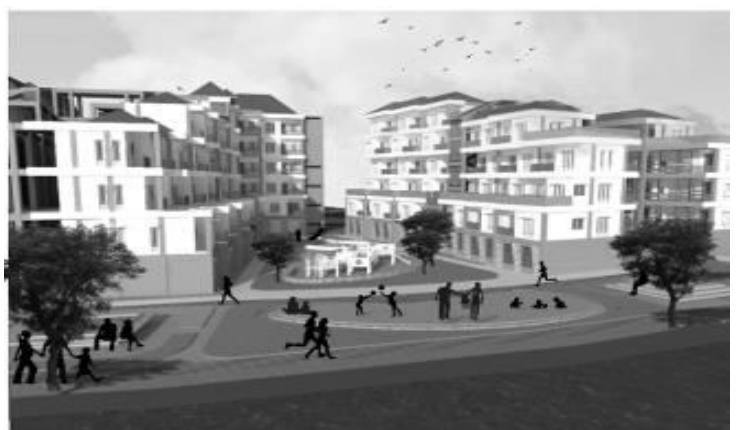

Gambar 7. Ilustrasi salah satu titik aktivitas bersama pada waterenjoyable-space.

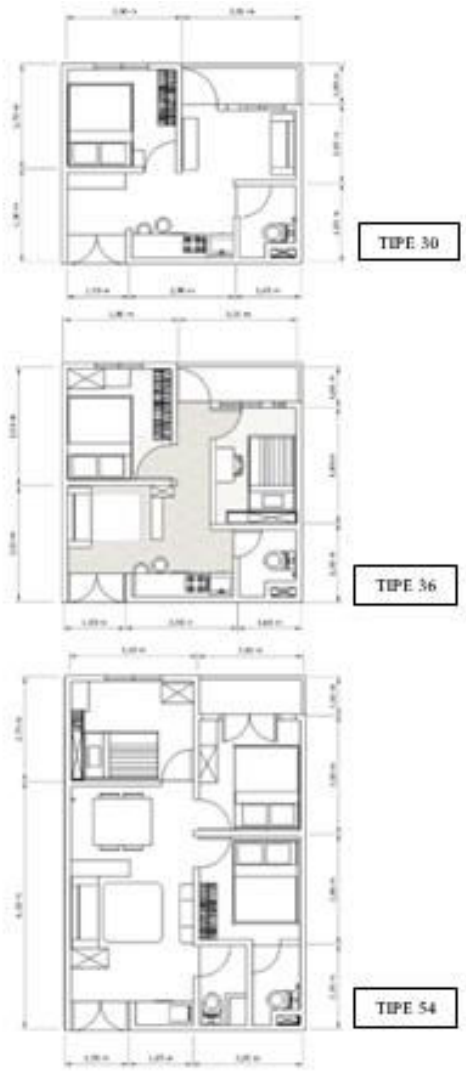

Gambar 8. Tipe-tipe unit hunian.

tempat/ lokasi. Metode ini lebih menekankan pada aktivitas di dalam hunian seperti belajar, makan dan minum, memasak, menyetrika, berkumpul dengan keluarga, menerima tamu, istirahat, mencuci, dll. Perilaku ini yang akan ditranslasikan ke desain unit hunian.

\section{HASIL PERANCANGAN}

Sebagai objek rancangan residential waterfront, yang harus terlihat dari sungai adalah image hunian, sehingga penempatan hunian berada di selatan. Sedangkan fasilitas lainnya berada di belakang hunian seperti pada gambar 3. Selain dikarenakan tuntutan dari konsep waterfront, zonasi ini juga sesuai dengan peruntukan lahan yang ada di tapak.

Lahan memiliki bentuk menyerupai tembereng atau irisan lingkaran, sehingga tatanan massa yang mengikuti bentuk

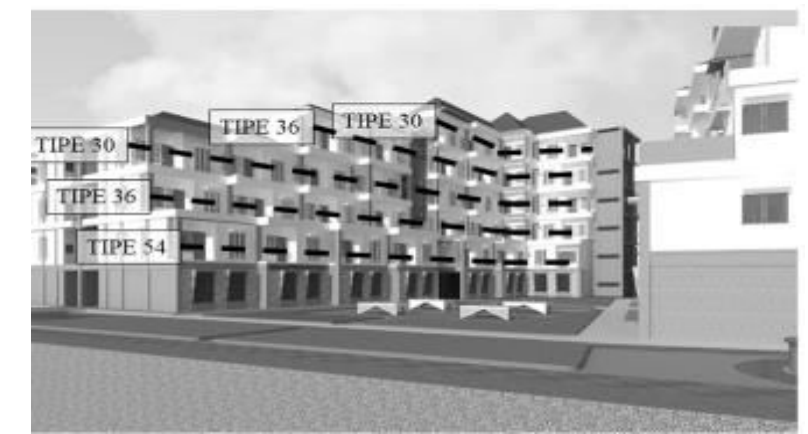

Gambar 9. Perspektif tower A..

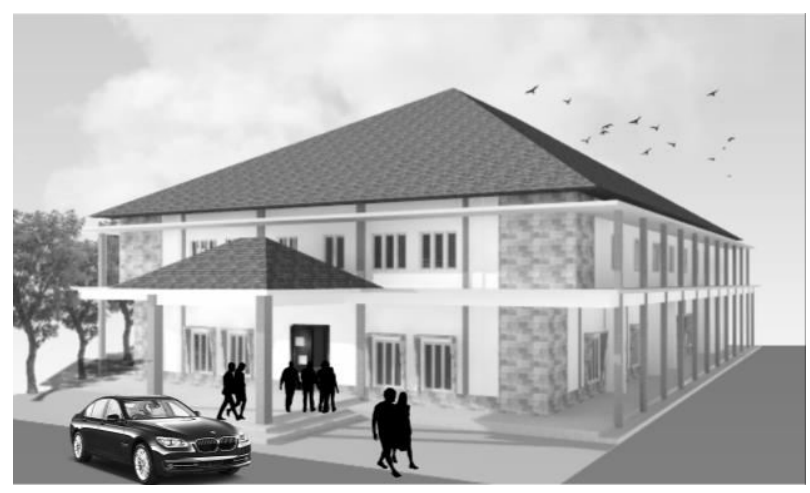

Gambar 10. Perspektif gedung serbaguna.

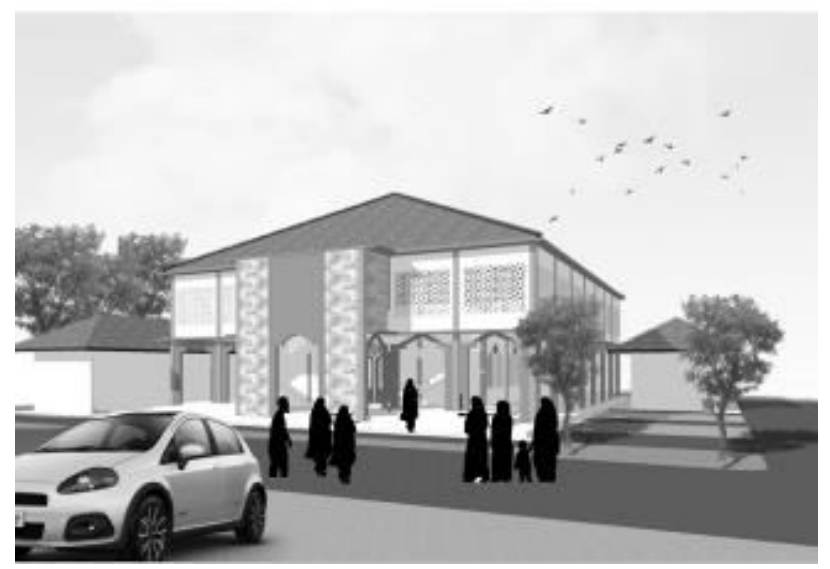

Gambar 11. Perspektif masjid.

lahan adalah yang berpusat pada pusat lingkaran yang terbentuk. Sesuai konsep waterfront, pola susunan massa mengikuti karakter alami kawasan (aliran sungai) dan berpusat pada titik lingkaran yang terbentuk seperti pada gambar 4 . Bangunan (hunian) memiliki orientasi ke badan air.

Pertemuan jalan/persimpangan jalan diterjemahkan dengan plaza yang diapit oleh 2 tower seperti gambar 5. Ruang bersama sebagai tempat bersosialisasi yang biasanya di gang/jalan diterjemahkan pada selasar dan jembatan penghubung antar tower seperti Gambar 6.

Ruang bersama pada luar bangunan terletak di sepanjang tepi sungai dan selanjutnya disebut dengan water-enjoyablespace. Sesuai kebiasaan penghuni, zona water-enjoyablespace menjadi ruang bersama bukan hanya untuk mereka namun juga masyarakat sekitar sehingga taman ini bersifat 
semi-privat. Terdapat beberapa titik aktivitas bersama untuk menampung aktivitas warga disepanjang zona ini seperti Gambar 7. Penempatan jalur pejalan kaki dan jogging track berada di sepanjang tepi air. Sirkulasi ini menghubungkan setiap titik aktivitas bersama pada zona water-enjoyable-space dan plaza antar tower.

Tiap unit hunian memiliki balkon untuk bisa mengakses visual sungai dari masing-masing unit. Terdapat 3 tipe hunian yaitu 30 untuk 1- 2 orang, 36 untuk 3-4 orang dan 54 untuk keluarga besar (lebih dari 4 orang) seperti gambar 8 .

Penataan unit hunian dalam 1 tower dibuat berbeda tipe tiap lantai agar memiliki pembayangan pada unit di bawahnya seperti gambar 9 .

Untuk mendukung keberlangsungan kegiatan bersosial di kawasan atau ini sebagai lahan permukiman dibutuhkan fasilitas penunjang berupa gedung serbaguna, masjid, dan area pendidikan berupa balai pelatihan untuk meningkatkan keterampilan peghuni dan PAUD seperti pada gambar 10 dan gambar 11. Hal ini didasarkan pada kebutuhan penghuni dan standar yang berlaku untuk sebuah kawasan permukiman.

\section{KESIMPULAN}

Desain hunian vertikal dengan konsep waterfront architecture ini adalah salah satu gagasan untuk menjawab permasalahan permukiman tepi sungai yang menempatkan sungai sebagai muka depan suatu kawasan. Dengan pendekatan perilaku untuk memindahkan masyarakat yang semula hidup di hunian horizontal ke hunian vertikal yang sesuai dengan kebutuhan dan perlaku mereka sebelumnya sehingga penghuni merasa nyaman di lingkungan baru. Harapannya dengan adanya water-enjoyable-space kebiasaan yang dapat menjadikan kumuh kawasan tepi sungai dapat diminimalisir dan menjadikan tepian sungai bukan lagi menjadi bagian belakang dari suatu kawasan.

\section{DAFTAR PUSTAKA}

[1] M. Nur and S. Winoto, Kebijakan Perkembangan Perkotaan, 1st ed. Malang: UB Press, 2004.

[2] T. Firman, "Menuju Model Pengembangan Wilayah Terbelakang: Kasus Jawa Barat Selatan,” Bandung, 2005.

[3] A. Dianingrum and et al, "The Efficiency of Settlement Land Arrangement Case Study: Taman Gunung Anyar Housing in Surabaya," Int. J. Sci. Technol. Res., vol. 6, no. 1, 2017.

[4] Soenyono, "Perkembangan Permukiman di Bantaran Sungai Surabaya dari Perspektif Sosiologi," J. Penelit. Hum., vol. 11, no. 2, pp. 85-101, 2006.

[5] H. Hidayat, "Lorong Tepian Sungai sebagai Ruang Komunal bagi Pemukim Marjinal," Palembang, 2014.

[6] E. Poedjioetami, "Penataan Ulang Kawasan Bantaran Sungai dengan Menghadirkan Sentra Ekonomi dan Rekreasi Kota Studi Kasus Kawasan Dinoyo Tenun, Surabaya," J. Rekayasa Perenc., vol. 4, no. 3, 2008.

[7] H. B. Setiawan, Arsitektur, Lingkungan dan Perilaku. Yogyakarta: Gadjah Mada University Press, 2010. 